\title{
Case Study on Pneumothorax with Massive Subcutaneous Emphysema after Supraclavicular Block
}

\author{
Meena Shyam C ${ }^{1}$, Tripathi Archana ${ }^{2}$, Joshi Adhokshaj ${ }^{3}$, Singhal Manoj ${ }^{3}$, \\ Meena Samta ${ }^{4}$, Khedia Chiranji Lal ${ }^{4}$, Nagar Satyanarayan ${ }^{4}$ \\ 1 - Senior resident in anaesthesiology, 2- Professor in anaesthesiology, 3 -Assistant professor in \\ anaesthesiology, 4-Junior resident in anaesthesiology \{Government medical college and attached hospitals, \\ Kota, Rajasthan, INDIA\}
}

\section{Case Study}

A 42 years old female referred in our tertiary care centre with history of road side accident (2014-1108), with degloving injury of left lower limb and left upper limb injury for K-wiring and debridement.

After checking base line investigation and fasting condition (all investigation including chest- $\mathrm{X}$ ray, ECG and CBC were within normal limit except low $\mathrm{HB}$ of $9 \mathrm{mg} / \mathrm{dl}$ ) anaesthetic plan was prepared. Spinal anaesthesia started for lower limb surgery by using free flow of CSF technique with $27 \mathrm{G}$ quincke's needle and $2 \mathrm{ml}$ of $0.5 \%$ bupivacaine heavy. Case started and completed smoothly with stable haemodynamics.

Near closure of lower limb procedure, supraclavicular brachial plexus block tried by blind technique by paraesthesia eliciting. Three attempts were taken, but could not achieve adequate level of surgical anaesthesia because patient became irritable and coughing. Mean while patient developed hypotension and little tachycardia, at that time managed with intravenous fluid and shifted the patient to recovery ward with instructions of chest-X ray and blood transfusion.

After few hours patient developed severe hypotension and respiratory distress. Same time she developed diffuse swelling that was confined over neck and chest region initially. Physician made differential diagnosis of angioneurotic oedema; blood transfusion related side effects and advised for supportive management.

After quick assessment of patient; kept on oxygen and advised for shifting of patient to ICU for further management. Dopamine infusion started and NIV bipap was started in ICU with low PEEP by junior resident for temporary purpose but within 30 minutes patient became more restless and haemodynamic parameters became quite unstable. Diffuse swelling became more significant and extends up to face and periorbital area above and reached up to whole abdomen area.

In arterial blood gas analysis we found significant hypoxia ( $\mathrm{paO}_{2}<40 \mathrm{~mm} \mathrm{Hg}$ ). We decided to detache the BiPAP and intubate the patient and kept on T-piece with high flow oxygen.

By palpating subcutaneous swelling we found characteristic egg shell crackling feel of subcutaneous crepitations; in chest-X ray we found minimal pneumothorax with massive emphysema. Than we made multiple skin nick and started milking, but saturation was not improving. Finally we inserted the chest tube connected with water seal drain bag in same side of pneumothorax under all aseptic precautions.

There was not clear cut indication of chest tube insertion because there was minimal pneumothorax component but there was need for effective ventilation for treating hypoxia and respiratory distress. After putting chest tube, we started ventilation with very low PEEP of 3-5 mm of $\mathrm{Hg}$. Manual milking of subcutaneous tissue was started. Patient kept on minimal sedation with fentanyl and midazolam infusion. It was beneficial in view of its analgesic property which was needed for pain that was occurring because of bilateral intercostal drain tubes. Intravenous dexamethasone and broad spectrum antibiotics were administered empirically.

After 5-6 hours patient gained consciousness and saturation picked up from 50\% to 90-92\%. Vital parameters became stable, inotropic supports gradually tapered and finally stopped. By effective lung protective mechanical ventilation, skin nicking and proper milking of chest area the diffuse swelling got settled down. Gradually weaned off from ventilator and extubated on $3^{\text {rd }}$ day.

After extubation we encouraged her and started effective physiotherapy and respiratory breathing exercises by using insentive spirometery. After $48 \mathrm{hrs}$ of nil drain in chest drain bags, ICD tube removed. The patient then shifted to general ward. After 3 days of that we did upper limb surgery under general anaesthesia with stable haemodynamics. 


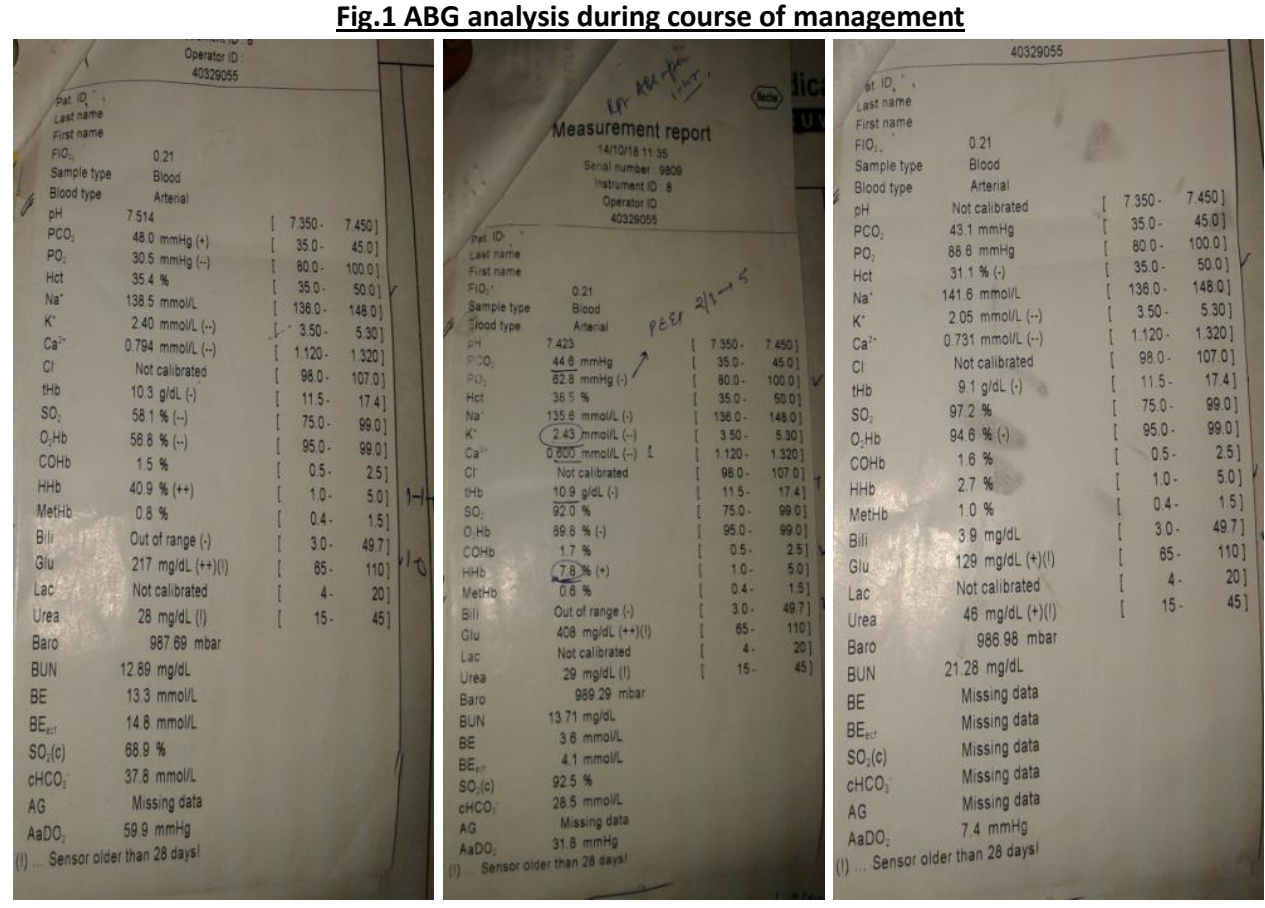

After pneumothorax and emphysema After complete resolution at the time of discharge
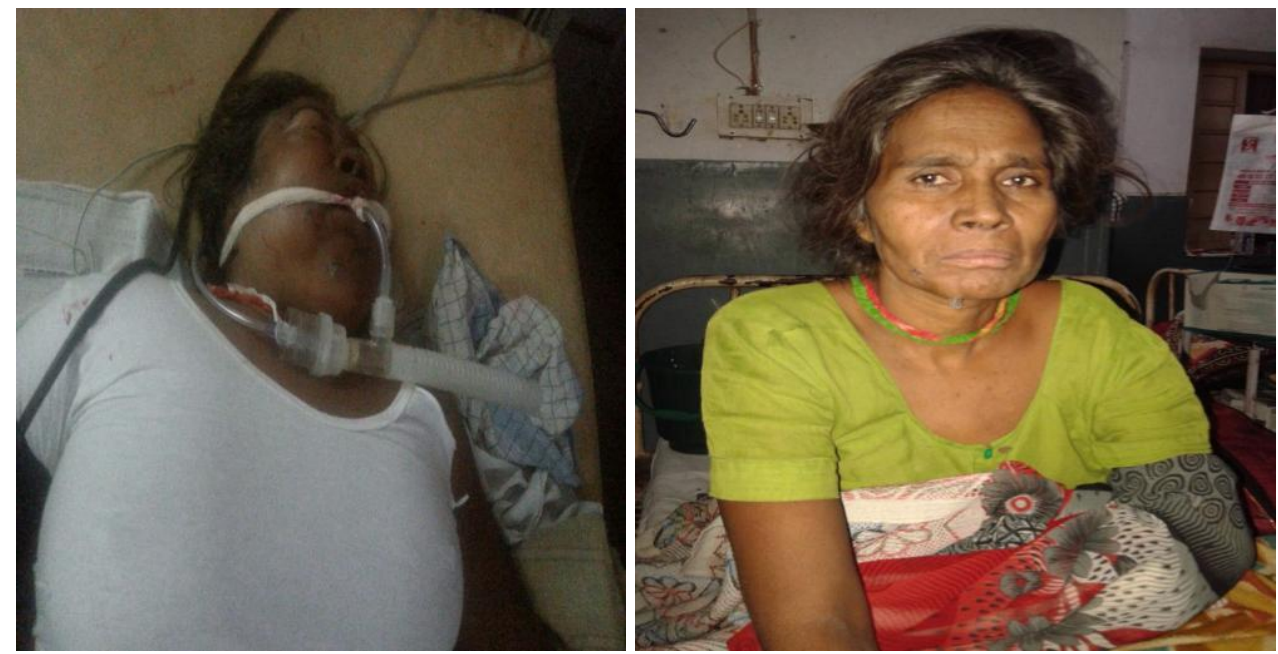

Fig.2

\section{Discussion}

Brachial plexus is formed by combination of anterior roots of inferior cervical spinal nerves (C5-C8) and the first thoracic nerve (T1), which extend anterolaterally and inferiorly after leaving the intervertebral foramens and is placed between anterior and middle scalenous ${ }^{2}$ muscles and then combine with each other to form three trunks that descend along the lateral border of the first rib and posterior of middle portion of clavicle to enter axilla. ${ }^{1-3}$ Brachial plexus blocking can be performed in interscalenous region over roots and in supraclavicular and infraclavicular regions, over trunks, and in axillary's region over branches by injecting local anesthetic drugs such as lidocaine. ${ }^{1,2,4}$

There are multiple methods including conventional supraclavicular block, supraclavicular perivascular block, supraclavicular para vascular block, classic technique and plumb bob technique that have been used. All block can be done by using one of these technique i.e. Ultrasound guided, peripheral nerve stimulating, blind paraesthesia technique. ${ }^{5}$ In classic technique, the needle is inserted from posterior border of sternocleidomastoid muscle at the end of interscalenous sulcus about $1 \mathrm{~cm}$ above the midclavicular point with posteroinferomedial angle for anesthesia; and palpation of artery is helpful in this point. ${ }^{1,5}$ 
Supraclavicular block is associated with complications some of which depends completely to physician experience. Reported complications include pneumothorax, vascular damage, hematoma, nerve damage, phrenic nerve block, Horner's syndrome, recurrent laryngeal nerve block and drug toxicity. ${ }^{5}$ $1.9 \%-2.2 \% .^{8,9}$

The drug toxicity is infrequent $(1.4 \% \text { to } 2 \%)^{6,7}$ and nerve injury have been reported to vary from

Pneumothorax rarely requires placement of chest tube. Except for pneumothorax, other complications appear rapidly after block and disappear spontaneously after end of drug effect. ${ }^{1,5}$

Subcutaneous emphysema can result from puncture of parts of the respiratory or gastrointestinal systems. Particularly in the chest and neck, air may become trapped as a result of penetrating trauma.(e.g., gunshot or stab wounds) or blunt trauma. Infection (e.g., gas gangrene) can cause gas to be trapped in the subcutaneous tissues. Subcutaneous emphysema can be caused by alpha-1-antitrypsin enzyme deficiency. ${ }^{10}$ Other common causes are pneumothorax and a chest tube that has become occluded by a blood clot or fibrinous material. It can also occur spontaneously due to rupture of the alveoli with dramatic presentation. ${ }^{11}$ When the condition is caused by surgery it is called surgical emphysema. ${ }^{12}$ The term spontaneous subcutaneous emphysema is used when the cause is not clear. ${ }^{11}$ Subcutaneous emphysema is not typically dangerous in and of itself; however it can be a symptom of very dangerous underlying conditions, such as pneumothorax. ${ }^{13}$ Although the underlying conditions require treatment, subcutaneous emphysema usually does not; small amounts of air are reabsorbed by the body. However, subcutaneous emphysema can be uncomfortable and may interfere with breathing, and is often treated by removing air from the tissues, for example by using large bore needles, skin incisions or subcutaneous catheterization. In case of massive emphysema sometime chest tube insertion with water seal drainage is quite beneficial.

In our case most likely causes of all consequences were accidental breach in the pleura during block, delay in making diagnosis and overenthusiastic application of bipap-NIV.

Therefore following guideline should be follow in such scenario.

- In patient who is having both limb (upper and as well as lower limb) injury for surgery general anaesthesia is best modality if there is no contraindication.

- Ultrasound guided supraclavicular block for upper limb surgery for preventing complications because of real time assessment of needle, drug and surrounding structures. ${ }^{14}$

- Complication can occur at any stages and with experience hand too, but early diagnosis and early management is essential for better outcome.

- For pneumothorax early insertion of chest tube under seal water drainage under all aseptic precaution and proper care of ICD tube.

- $\quad$ Bipap -NIV should be avoided in patient with pneumothorax and subcutaneous emphysema following unintentionally pleura breach. Because application of NIV or PEEP can worse the conditions and will increase the magnitude of pneumothorax and emphysema as well.

\section{References}

[1]. Miller RD. Anesthesia, vol 2, 5th ed. Churchill Livingston, USA, 2000; 1523-4.

[2]. Berry FR. Supraclavicular Brachial Plexus Block, Anesthesia \& Intensive Care, Edgecliff, 2000;28:708

[3]. Hinrich MH. Infra-clavicular plexus block: Two approaches, Abteilung Anesthesiologie/Intensiumedizin

[4]. Brown DL.Atlas of Regional Anesthesia. 2nd ed. Saunders, USA, 1999;33-9.

[5]. Green DP. Operative Hand Surgery, Vol 1.3rd ed. Churchill Livingston, USA, 1993; 26-32.

[6]. Fincan B. Complication of Brachial Plexus anesthesia. 20, Sep 2002

[7]. Brown DL, Ransom DM. Hall JA. Regional anesthesia and local anesthetic induced systemic toxicity: Seizure frequency and accompanying cardiovascular changes. Anesth Analg, 1995; 8: 321.

[8]. Salander D, Edshage S, Wolff T. Parenthesis or no parenthesis, Acta Anesthesiol Scand, 1979;23:27.

[9]. Auroy Y. Serious Complications related to regional anesthesia; Results of a prospective survey in France. Anesthesiology 1997; 87: 479-486.

[10]. Maunder RJ, Pierson DJ, Hudson LD (July 1984). "Subcutaneous and mediastinal emphysema. Pathophysiology, diagnosis, and management". Arch. Intern. Med. 144 (7): 1447-53.

[11]. Parker GS, Mosborg DA, Foley RW, Stiernberg CM (September 1990). "Spontaneous cervical and mediastinal emphysema". Laryngoscope 100(9): 938-940.

[12]. Oxford, UK: Oxford University Press. 2003. ISBN 0-19-860753-913. Brooks DR (1998). Current Review of Minimally Invasive Surgery. Philadelphia: Current Medicine. P. 36.ISBN 0-387-98338-4.

[13]. Perlas, G. Lobo, N. Lo, R. Brull, V. W. S. Chan, and R. Karkhanis, "Ultrasound-guided supraclavicular block: outcome of 510 consecutive cases," Regional Anesthesia and Pain Medicine, vol. 34, no. 2, pp. 171-176, 2009. 